\title{
Tracheobronchial Chondritis Associated with Immune Checkpoint Blockade
}

\author{
Tatsuma Asoh ${ }^{1}$, Toyoshi Yanagihara ${ }^{1}$, Risa Tanaka ${ }^{2}$ and Reiko Yoneda ${ }^{3}$
}

Key words: immune checkpoint inhibitor, immune-related adverse event, nivolumab, tracheobronchial chondritis

(Intern Med 60: 2517-2518, 2021)

(DOI: 10.2169/internalmedicine.6798-20)
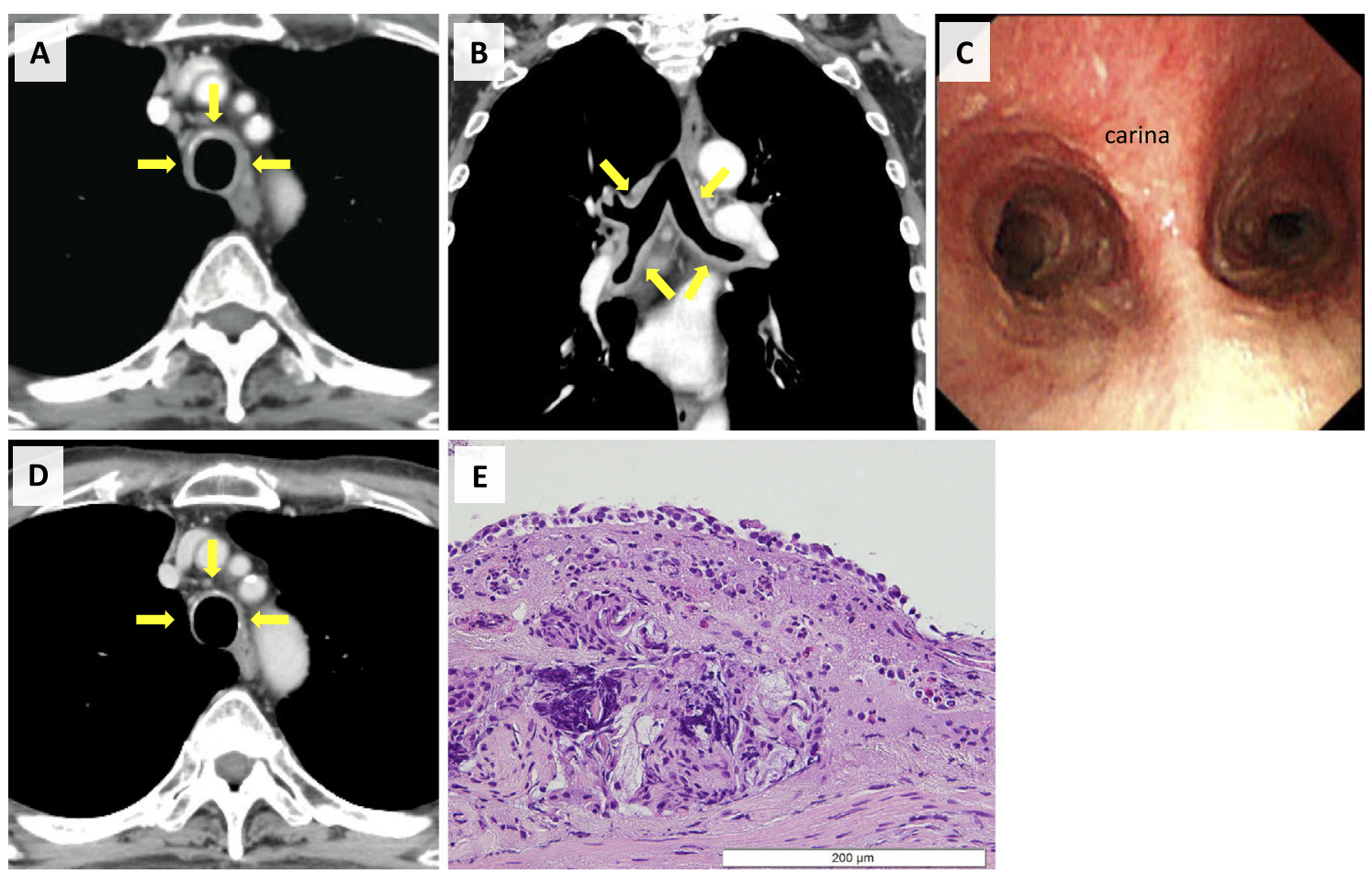

Picture.

A 68-year-old man was referred to the respiratory department with a 2-week history of progressively worsening productive cough and a fever. He had a history of laryngeal carcinoma treated with concurrent chemo-radiotherapy six years earlier. He had been diagnosed with esophageal carcinoma the year before. He had been administered 5fluorouracil and cisplatin as a first-line treatment and nivolumab as a second-line treatment for five months. His C-reactive protein level was elevated at $15.19 \mathrm{mg} / \mathrm{dL}$. Computed tomography of the chest showed diffusely thickened bronchial walls with no active lesions in the lung (Picture A, B). Bronchoscopy revealed diffuse, swollen erythematous mucosa, which resulted in the disappearance of the cartilaginous tracheobronchial ring structure (Picture C). A histologic examination revealed active inflammation with moderate lymphocytic infiltration in the bronchial tissue (Picture E). No pathogen was detected. Serum anti-type 2 collagen antibodies were positive (53.9 index; normal range $<20)(1)$. There were no cartilage abnormalities in the other sites, including the ears and the nose. A diagnosis of

${ }^{1}$ Department of Respiratory Medicine, Hamanomachi Hospital, Japan, ${ }^{2}$ Department of Medical Oncology, Hamanomachi Hospital, Japan and ${ }^{3}$ Department of Anatomic Pathology, Hamanomachi Hospital, Japan

Received: November 26, 2020; Accepted: January 6, 2021; Advance Publication by J-STAGE: February 22, 2021

Correspondence to Dr. Toyoshi Yanagihara, yanagiha@kokyu.med.kyushu-u.ac.jp 
nivolumab-induced tracheobronchial chondritis was made. The patient was treated with $50 \mathrm{mg}$ /day of prednisolone followed by tapered dosing. Tracheobronchial chondritis and associated symptoms were resolved (CT imaging 14 days after treatment: Picture D).

Written consent for publication was obtained from the patient.

The authors state that they have no Conflict of Interest (COI).

\section{Reference}

1. Kuba $\mathrm{K}$, Nakahira $\mathrm{M}$, Inoue $\mathrm{H}$, Kogashiwa $\mathrm{Y}$, Ebihara $\mathrm{Y}$, Sugasawa M. Nivolumab-related tracheobronchial chondritis: extremely rare manifestation of an immune-related adverse effect. Head Neck 42: E43-E48, 2020.

The Internal Medicine is an Open Access journal distributed under the Creative Commons Attribution-NonCommercial-NoDerivatives 4.0 International License. To view the details of this license, please visit (https://creativecommons.org/licenses/ by-nc-nd/4.0/).

(C) 2021 The Japanese Society of Internal Medicine Intern Med 60: 2517-2518, 2021 